\title{
Docência na Educação Superior: empreendedorismo e a ordem do discurso
}

\author{
Teaching in university education: \\ entrepreneurship, innovation and the order of the discourse
}

\author{
Docencia en la Educación Superior: \\ emprendedorismo y el orden del discurso
}

DANIELA PEDERIVA PENSIN ${ }^{*}$

Universidade do Oeste de Santa Catarina, Xanxere- SC, Brasil.

\begin{abstract}
RESUMO: Tendo o discurso como conceito teórico-metodológico, o texto explora as relações entre educação superior e mercado, tomando projetos pedagógicos institucionais de universidades para análise. Recorrências indicam o discurso do empresariamento e uma docência constituída por dois imperativos: empreendedorismo e inovação. Na ordem do discurso, está uma forma singular de docência vinculada a uma concepção de educação que, presente nesta lógica, atende a uma vontade de verdade e mobiliza as instituições a constituir-se no verdadeiro, respondendo assertivamente às demandas que este contexto apresenta.
\end{abstract}

Palavras-chave: Discurso. Empreendedorismo. Inovação.

\begin{abstract}
This paper explores the relation between university education and the market taking institutional pedagogical projects as analytical surface having the speech as a methodological and theoretical concept. The recurrences found here show that the discourse of entrepreneurship as convergence and the teaching made up of two imperatives: entrepreneurship and innovation. Amidst the order of the speech there is a singular way of teaching linked to a concept of
\end{abstract}

* Doutora em Educação pela Universidade do Vale do Rio dos Sinos. É professora titular da Universidade do Oeste de Santa Catarina e professora do Programa de Pós-graduação da mesma instituição. É líder do Grupo de Estudos e Pesquisas em Docência na Educação Superior. E-mail:<daniela.pensin@unoesc.edu.br>. 
education that corresponds to the truth and moves the institutions to come to the true, responding assertively to the demand of this paper. Keywords: Discourse; entrepreneurship; innovation.

RESUMEN: Con el discurso como concepto teórico-metodológico, el texto explora las relaciones entre educación superior y mercado, tomando proyectos pedagógicos institucionales de universidades para análisis. Las recurrencias indican el discurso del empresariado y una docencia constituida por dos imperativos: carácter emprendedor e innovación. En el orden del discurso, está una forma singular de docencia vinculada a una concepción de educación que, presente en esta lógica, atiende a una voluntad de verdad y moviliza las instituciones a constituirse en el verdadero, respondiendo asertivamente a las demandas que este contexto presenta.

Palabras clave: Discurso. Carácter emprendedor. Innovación.

\section{Primeiras aproximações}

E ste texto apresenta um conjunto de argumentações e reflexões, considerando a constituição da docência na educação superior implicada por uma ordem do discurso de racionalidade neoliberal, que provoca o estreitamento das relações entre educação superior e mercado, sustentando-as a partir de uma lógica que traz imperativos às instituições de ensino superior (IES). Parto do princípio de que há certa ordem do discurso sobre a educação superior, uma discursividade que implica o ordenamento e regulação das IES e da docência. Com isso quero dizer que "há determinadas regras que sancionam ou interditam a produção e a circulação de práticas discursivas" (SOMMER, 2007: 58) implicadas na constituição de docências singulares, presentes neste mundo e neste tempo.

A abordagem teórico-metodológica de inspiração foucaultiana que guia o texto considera que a noção de discurso rompe com os sentidos correntes do campo da linguística, calcados no binarismo significante-significado (SOMMER, 2007). Os discursos são, na perspectiva deste artigo, práticas organizadoras da realidade. Ainda que feitos de signos, "o que fazem é mais que utilizar esses signos para designar coisas. É esse mais que os torna irredutíveis à língua e ao ato da fala" (FOUCAULT, 2014: 56). Os discursos estabelecem hierarquias, distinções, articulam o visível e o dizível, organizam as relações entre indivíduos, instituições e as organizações sociais. 
A produção dos discursos é controlada e regulada por diversos procedimentos. Há ditos sancionados e outros interditados. O que é dito na e sobre a educação superior e a docência neste nível de ensino repercute porque referendado por uma ordem mais ampla, porque presente na ordem do discurso (FOUCAULT, 2012). Na abordagem aqui apresentada, os discursos são considerados monumentos, "o que implica operar sobre os ditos, sobre a superfície dos textos, sem buscar um suposto significado subjacente à sua materialidade" (SOMMER, 2007: 59).

Construído a partir de pesquisa que fez uso do discurso como conceito teórico-metodológico, o texto explora a temática das relações entre educação superior e mercado tomando os projetos pedagógicos institucionais (PPI) de nove universidades do Rio Grande do Sul ${ }^{1}$ como superfície analítica, relacionando elementos que possibilitam discutir as implicações do movimento de empresariamento à constituição de uma docência singular, presente no verdadeiro, segundo a ordem do discurso. Ao perguntar sobre os discursos que as universidades fazem reverberar por meio de seus PPI, a pesquisa orientou a análise dos materiais a buscar pelas recorrências discursivas que mostram aquilo que a instituição seleciona para dizer de si, dando visibilidade às verdades que assume sobre a educação superior e, consequentemente, sobre a docência.

\section{O discurso do empresariamento da ES}

Discursos circulam, positivam e disseminam modos de ser e fazer. Em Arqueologia do Saber, Foucault (2014:131) define discurso como "conjunto de enunciados que se apoia em um mesmo sistema de formação" ou uma mesma formação discursiva. Amparados em bases institucionais, os discursos encontram mecanismos de coerção e participam de jogos de verdade. É em meio à discursividade do presente que circulam verdades 'deste mundo', condições de possibilidade para a constituição de discursos sobre a educação superior desde a perspectiva neoliberal que a tomam como um investimento de produção de subjetividades úteis ao jogo econômico.

Os materiais analisados fazem ver que a educação superior está inscrita no "conjunto de ações de poder que objetivam conduzir (governar) deliberadamente a própria conduta ou a conduta dos outros" (VEIGA-NETO; LOPES, 2007: 952). É uma potente ação de condução da conduta (BIESTA, 2013), uma intervenção na vida de alguém de maneira a torná-lo outro alguém, supostamente melhor. O sujeito que serve de referência às propostas formativas das universidades tomadas para estudo ${ }^{2}$ é concebido como crítico, consciente, responsável - homens que "defendam valores e ações embasados na ética, na justiça, na dignidade e na solidariedade" (PPI V, 2011:10), que possam atuar "no sentido da superação da pobreza, da intolerância, do analfabetismo, da fome, da degradação do meio ambiente e de todas as formas de violência e de exclusão individual 
e social" (PPI VI, 2012: 27), devendo "ser dotado[s] de autonomia, de senso crítico e de responsabilidade, em uma perspectiva humanística" (PPI VII, 2008: 19).

Está o presente marcado pelo que considero 'movimento de empresariamento' da educação superior. Tal movimento faz com que as IES assumam para si uma racionalidade que tem a empresa como referência e passem a valorizar produtividade, eficácia, sustentabilidade econômica, competitividade, inovação e empreendedorismo. À educação superior cabe mobilizar estratégias que refiram um investimento do/no sujeito cujo propósito está na usabilidade dos corpos, na otimização de suas potencialidades (TREVISAN; ROSA, 2016), uma vez que "o profissional [a ser formado pela IES] deve ser capaz de dar respostas concretas e imediatas aos problemas que surgem em sua atividade diária, quando engajado no mercado de trabalho" (PPI IV, 2012: 81).

Inserida nessa lógica de empresariamento, a educação superior atua de modo a produzir efeitos planejados; atua na produção de sujeitos potencializados que empreendem sobre si mesmos e sobre a sociedade, que atuam potentemente sobre si e sobre o meio (PENSIN, 2017). Desde meados do século XX as IES passaram, lenta e continuadamente, a orientar-se por uma proposta de gestão empresarial; além disso, em busca de sua sustentabilidade econômica e financeira, orientaram sua atuação à flexibilidade das exigências do mercado (BECHI, 2011). Trata-se não apenas da compreensão das IES como empresas, mas, da consideração de que orientar-se por uma racionalidade empresarial é a melhor forma de alcançar desempenho de qualidade, cumprir seu compromisso social e a conduzir racionalmente a vida acadêmica. O que se vê "é a disseminação da forma de mercado ou empresarial como narrativa-mestra que define e confina toda a variedade de relações dentro do Estado e entre o Estado, a sociedade civil e a economia" (BALL, 2010: 50).

No Brasil, as finalidades atribuídas pela legislação ${ }^{3}$ à educação superior não deixam dúvidas sobre a inerente vinculação com o mercado de trabalho dada a natureza dos processos de profissionalização com os quais está implicada. Não se trata aqui da negação desta articulação e sim da problematização da educação superior tomada por uma lógica de empresariamento como fato posto, da naturalização da noção de conhecimento como mercadoria e educação como serviço.

Ao assumir a lógica da empresa, os compromissos formativos institucionais passam a ser orientados por perfis de egressos cujas competências são frequentemente orientadas ao gerenciamento, à flexibilidade, ao enfrentamento de desafios, à inovação, ao empreendedorismo, apenas para citar algumas qualificações. Vê-se manifestações como "capacidade para trabalhar em grupo, gerenciar processos para atingir metas, trabalhar com prioridades, avaliar, lidar com as diferenças, enfrentar os desafios das mudanças permanentes, resistir às pressões, desenvolver o raciocínio lógico-formal aliado à intuição criadora" (PPI VI, 2012: 38-9). Destaco que esses perfis de egresso são institucionais, desejados aos alunos pertencentes a todos os cursos de graduação, e não apenas àqueles que possuam vinculação direta com a formação empresarial. Há neles também a 
compreensão de que "a formação profissional não é mais homogênea, uma vez que o mundo do trabalho se orienta mais para o livre empreendedorismo do que para a preparação para o emprego" (PPI I, 2006: p.11).

Muito embora as funções da educação superior não estejam restritas à formação para o mercado de trabalho e envolvam a formação humana e cultural, indo além de processos de qualificação técnica (TREVISAN; ROSA, 2016), a educação superior constitui-se em meio às discursividades do presente. Mobiliza discursos inseridos em uma ordem do discurso própria deste período particular. Tal ordem do discurso possui "uma função normativa e reguladora e estabelece mecanismos de organização do real por meio da produção de saberes, de estratégias e de práticas" (REVEL, 2011: 41). Desse modo, os discursos sobre a educação superior presentes na materialidade dos PPI constituem-se em possibilidade de normatização, regulação e organização da docência, na medida em que discursam verdades ou 'o verdadeiro' sobre ela em relação a este período particular, o presente. Trata-se de "um discurso que não seja unicamente o da moral, mas da racionalidade" (FOUCAULT, 1999: 26). É esta constituição - em meio a discursos de uma racionalidade neoliberal acentuada por uma lógica de empresariamento da educação superior - que traz consigo os imperativos do empreendedorismo e da inovação à docência, focos da seção a seguir.

\section{Os imperativos à docência}

Muito embora haja sempre a possibilidade de rotas de fuga e não se possa desconsiderar a complexidade das problemáticas que envolvem a educação superior, o exercício analítico trouxe uma docência que é construída e se faz a si mesma a partir de dois imperativos: (1) o do empreendedorismo, uma ação do sujeito sobre si mesmo de modo a tornar-se aquilo que deva ser, mobilização de estratégias na direção da eficiência e da produtividade, fazendo de si um sujeito performático; (2) o da inovação, que aponta para uma inovação que faça mais do mesmo, que toda inovação seja na direção do atendimento ao mercado.

Há, na materialidade destes discursos, a verdade de que a educação superior se orienta por e para uma lógica de empresariamento que faz da universidade uma agência, um "lugar onde se tratam negócios" (CUNHA, 2007: 43), lugar de prestação de serviços, de atendimento a interesses de mercado, que, ao que parece, passa a ser tomado como sinônimo de sociedade. É, assim, a universidade uma organização que tem com o aluno e com a sociedade/mercado uma relação de clientela, pois cabe a ela e aos professores “compreender e atender as necessidades e expectativas dos alunos" (PPI VI, 2012: 74). Trata-se da presença recorrente de discursos em que prevalecem elementos relacionados à produtividade, à competitividade, à concorrência, ao empreendedorismo, à inovação técnica, ao pragmatismo e ao ajuste entre o conjunto de ofertas e de demandas de emprego. 
O recorrente discurso de mercado que movimenta perspectivas empresariais num processo de mercadificação da educação (PERONI, 2016) traz o empreendedorismo e a inovação como imperativos à docência e postos como características do perfil dos egressos. Há vinculação da inovação e do empreendedorismo à produção de pesquisa e tecnologia; estímulo à metodologia de ensino "inovadora" e orientada pela aprendizagem. Os PPI valorizam a parceria com empresas e com o mundo do trabalho visto que, "além de contribuírem para a qualificação profissional [...] captam novas demandas nos currículos para a garantia de uma formação inovadora, atenta às transformações contemporâneas" (PPI III, 2011: 20). Estas parcerias são indicadas como orientadoras das alterações curriculares nos cursos, dos modos e práticas de docência já que "as mudanças ocorridas no mundo do trabalho passam a exigir realmente uma nova relação com o conhecimento" (PPI VI, 2012:53).

Coloca-se a inovação como característica do sujeito requerido pelo mercado de trabalho, capaz de inovar na proposição de soluções, revertendo em maior empregabilidade por parte do egresso e qualidade por parte da IES. O destaque dos documentos à noção de inovação articulada à lógica do mercado está presente em todos os PPI analisados e ela chega a ser apontada como elemento identitário da IES, expressado pelo desejo de ser reconhecida como inovadora ou pela inovação que promove, já que a inovação é considerada um indicador de sucesso. As verdades que estas posições institucionais fazem circular reconhecem o valor positivo atribuído à inovação, uma vez que a adjetivação 'inovadora' torna a IES mais potente em termos de competitividade, mais adequada em relação às funções que, supõe, deva cumprir.

No presente, empreendedorismo e educação parecem cada vez mais aproximados. Torna-se quase 'natural' que a docência atue na formação do empreendedor, que, como agente que atua sobre si mesmo e sobre o meio, é considerado útil à sociedade. As relações entre educação e empreendedorismo trazem impactos à constituição da docência e do docente. O indivíduo "assume o lugar de empresário de si mesmo" (SILVA, 2011: 139) e, por isso, assume a responsabilidade sobre si, sobre seu fracasso ou sucesso, sobre seus diferenciais competitivos e sua produtividade. Esses indivíduos - e aqui entendo tanto estudantes quanto professores - são conduzidos a serem empreendedores, são indivíduos de investimentos permanentes, "são pró-ativos, inovadores, inventivos, flexíveis, com senso de oportunidade, com notável capacidade de provocar mudanças, etc.” (SILVA, 2011: 140).

Com bastante frequência, os documentos expressam posições institucionais, manifestando a compreensão de que a educação é uma ação capaz de desenvolver uma espécie de espírito inovador e empreendedor no indivíduo, caracterizando-o como profissional requerido pelo mercado de trabalho. Vemos manifestações nesta direção nos trechos que defendem: a necessidade de a "ação acadêmica contemplar desafios que ensejem o despertar do espírito inovador e empreendedor do estudante" (PPI I, 2006: 20); o egresso como alguém "pró-ativo na resolução de desafios, respondendo-os com conhecimento e empreendedorismo" (PPI II, 2013: 40) e com conhecimentos "transponíveis de forma 
empreendedora" (PPI II, 2013: 51); um egresso "capaz de criar, prever, compartilhar, empreender e inovar" (PPI III, 2011: 15). Essa educação superior que enfatiza, valoriza e se orienta pela e para a inovação é também a que conduz práticas capazes de produzir sujeitos considerados agentes autônomos e empresários de si mesmos; que estão dispostos, como afirma Marin-Díaz (2015), a investimentos em seu capital, em sua potencialização para alcançar o sucesso, num mundo regido pelo mercado e pela economia.

A materialidade analisada possibilita ver aproximações entre a ideia de inovação e o emprego de recursos didáticos e tecnológicos nos processos de ensino e de aprendizagem. Vê-se a inovação a partir de práticas pedagógicas cujo objetivo é "fomentar ações educativas, metodologias e práticas inovadoras integradoras nos currículos dos cursos" (PPI VIII, 2010: 30). É a inovação um imperativo à prática pedagógica, passando a ocupar um status de verdade e a assumir uma posição de modelo a ser adotado. Ser inovador, ser formado de maneira inovadora, ser orientado e receptivo à inovação são questões que estão na ordem do discurso. O ensino e as práticas pedagógicas dos professores devem ser inovadores e, para inovar, os professores precisam adotar práticas presentes, todas, numa mesma racionalidade. Inovar é, assim, fazer mais do mesmo.

\section{Últimas considerações}

É neste contexto e dentro desta lógica - inclusive como estratégia de sobrevivência - que a educação superior no presente opera orientada pela ideia de formação do sujeito potencializado pela educação, com condições de responder positivamente à racionalidade de mercado porque possuidor de diferenciação competitiva, inovador, empreendedor, criativo, eficiente e flexível. É nesta trama que se vê enredada a docência na educação superior, em meio a jogos de verdade em que o discurso verdadeiro, como dizia Foucault (2012), não reconhece a vontade de verdade que o atravessa. Mais do que isso, "a vontade de verdade [...] é tal, que a vontade que ela quer não pode deixar de mascará-la" (FOUCAULT, 2012:19).

Assumind o a lógica de mercado como guia, as IES reverberam e oficializam discursos cujas bases servem a interesses não necessariamente ou prioritariamente educativos. Ao mobilizar discursos da lógica de mercado, intensificam os laços entre a educação superior e a racionalidade neoliberal e acabam por alimentar o contexto de empresariamento no qual se encontram. É como se, para sobreviver ou resistir às pressões e cerceamentos que esta lógica lhes impõe, as IES acabassem por 'alimentar o monstro', a enrolar-se mais e mais nas teias que as prendem. Esses discursos sobre a educação superior - e lembremos que os discursos constituem as coisas - dizem mais do mesmo. Cabe o estranhamento frente à ideia de ser esta a rota, o caminho a seguir e do qual não se pode desviar. Um caminho que, segundo as verdades que circulam e positivam formas de ser e agir, é bom, certo, adequado, promissor e nos conduzirá a uma vida melhor. 
Recebido em: 04/05/2018 e Aprovado em: 17/08/2018

\section{Notas}

1 Universidade Federal de Santa Maria (UFSM); Universidade Federal de Ciências da Saúde de Porto Alegre (UFCSPA); Universidade Federal do Pampa (UNIPAMPA); Universidade Federal do Rio Grande (FURG); Universidade de Passo Fundo (UPF); Universidade Luterana do Brasil (ULBRA); Pontifícia Universidade Católica do Rio Grande do Sul (PUCRS); Universidade Feevale (FEEVALE); Universidade de Cruz Alta (UNICRUZ).

2 Objetivando a simplificação na apresentação dos excertos, a identificação dos documentos está assim organizada: PPI I - Universidade de Passo Fundo (UPF); PPI II - Universidade Luterana do Brasil (ULBRA); PPI III - Pontifícia Universidade Católica do Rio Grande do Sul (PUC-RS); PPI IV - Universidade Federal de Santa Maria (UFSM); PPI V - Universidade Feevale (FEEVALE); PPI VI - Universidade Fundação Ciências da Saúde de Porto Alegre (UFCSPA); PPI VII - Universidade de Cruz Alta (UNICRUZ); VIII - Universidade Federal do Pampa (UNIPAMPA); PPI IX - Universidade Federal do Rio Grande (FURG).

3 Refiro-me especificamente à Lei de Diretrizes e Bases da Educação Nacional. Lei N. 9394/96, 20 de dezembro de 1996, art. 43, sobre as finalidades da educação superior.

\section{Referências}

BALL, Stephen J. Performatividades e fabricações na economia educacional: rumo a uma sociedade performativa. Educação \& Realidade, UFRGS: Porto Alegre, v.35, n. 2, p. 37-55, maio/ago., 2010.

BECHI, Diego. Mercantilização do ensino superior: os desafios da universidade diante do atual cenário educacional. Acta Scientiarum Education, UEM: Maringá, v. 33, n. 1, 139-147, 2011.

BIESTA, Gert. Para além da aprendizagem. Educação democrática para um futuro humano. Belo Horizonte: Autêntica, 2013.

BRASIL. Lei no 9. 394, de 20 de dezembro de 1996. Estabelece as diretrizes e bases da educação nacional. Disponível em: <<http://portal.mec.gov.br/arquivos/pdf/ldb.pdf> . Acesso em: 11 maio 2014.

CUNHA, Antônio Geraldo da. Dicionário etimológico da língua portuguesa. Rio de Janeiro: Lexikon Editora Digital, 2007.

FOUCAULT, Michel. A arqueologia do saber. Rio de Janeiro: Forense Universitária, 2014.

História da Sexualidade. Rio de Janeiro: Graal, 1999.

A ordem do discurso. Aula inaugural no College de France pronunciada em 2 de dezembro de 1970. São Paulo: Loyola. 2012.

FUNDAÇÃO UNIVERSIDADE FEDERAL DE CIÊNCIAS DA SAÚDE DE PORTO ALEGRE. Projeto Político-Pedagógico Institucional. Porto Alegre: Reitoria, 2008. 44 p.

GARCÍA, Araceli Estebaranz. Los caminos de la universidad. In: GARRIDO, Susane Lopes; CUNHA, Maria Isabel da; MARTINI, Jussara Gue (Orgs). Os rumos da educação superior. São Leopoldo:

Unisinos, 2002. 
JUNGES, Márcia; João SANTOS, Vitor. A antropotécnica que molda o indivíduo pela educação entrevista com Dora Marin-Díaz. Revista do Instituto Humanitas, São Leopoldo: Unisinos, ed. 472, 14.09.2015.

PENSIN, Daniela Pederiva. Agenciamento e docência na educação superior. 2017. 204f. Tese (Doutorado em Educação) - Universidade do Vale do Rio dos Sinos, São Leopoldo/RS, 2017.

PERONI, Vera Maria Vidal. Implicações da relação público-privada para a democratização da educação. In: Reunião científica regional da Anped: educação, movimentos sociais e políticas governamentais. v. 11. Curitiba: UFPR, 2016.

PONTIFÍCIA UNIVERSIDADE CATÓLICA DO RIO GRANDE DO SUL. Projeto Pedagógico Institucional. Porto Alegre: Reitoria, 2011. 24p.

REVEL, Judith. Dicionário Foucault. Rio de Janeiro: Forense Universitária, 2011.

SILVA, Roberto Rafael Dias da. A constituição da docência no ensino médio no Brasil contemporâneo: uma analítica de governo. 2011. 215 f. Tese (Doutorado em Educação) Universidade do Vale do Rio dos Sinos, São Leopoldo/RS, 2011.

SOMMER, Luis Henrique. A ordem do discurso escolar. Revista Brasileira de Educação. ANPED: Rio de Janeiro, v.12, n. 34, 57-67, jan./abr. 2007.

TREVISAN, Amarildo Luiz; ROSA, Geraldo Antonio. Biopolítica, formação cultural (bildung) e educação. In: Reunião científica regional da Anped: educação, movimentos sociais e políticas governamentais. v. 11. Curitiba: UFPR, 2016.

UNIVERSIDADE DE CRUZ ALTA. Plano de Desenvolvimento Institucional. Cruz Alta: Reitoria, 2010. $126 \mathrm{p}$.

UNIVERSIDADE DE PASSO FUNDO. Projeto Pedagógico Institucional. Passo Fundo: Reitoria, 2006. $41 \mathrm{p}$.

UNIVERSIDADE FEDERAL DE SANTA MARIA. Projeto Político-Pedagógico. Santa Maria: Reitoria, $2000.39 \mathrm{p}$.

UNIVERSIDADE FEDERAL DO PAMPA. Plano de Desenvolvimento Institucional. Bagé: Reitoria, 2014. $111 \mathrm{p}$.

UNIVERSIDADE FEDERAL DO RIO GRANDE. Projeto Pedagógico Institucional. Rio Grande: Reitoria, 2011. 12 p.

UNIVERSIDADE FEEVALE. Projeto Pedagógico Institucional. Novo Hamburgo: Reitoria, 2012. 265p.

UNIVERSIDADE LUTERANA DO BRASIL. Projeto Pedagógico Institucional. São Paulo: Reitoria, 2013. 127p.

VEIGA-NETO, Alfredo; LOPES, Maura Corcini. Inclusão e governamentalidade. Educação e Sociedade, Campinas: Unicamp, v. 28, n.100, p.947-963, out., 2007. 